\title{
Calcium Dipicolinate-provoked Germination and Outgrowth of Spores of Clostridium pasteurianum
}

\author{
By B. M. MACKEY AND J. G. MORRIS \\ Department of Botany and Microbiology, School of Biological Sciences, \\ University College of Wales, Aberystwyth, $S Y 23{ }_{3} \mathrm{DA}$
}

(Received I9 June 1972)

\begin{abstract}
SUMMARY
Germination of heat-activated spores of Clostridium pasteurianum was rapidly induced by treatment with calcium dipicolinate; $90 \%$ of the spores lost their refractility within $20 \mathrm{~min}$ at $37^{\circ} \mathrm{C}$. The sequence of ultrastructural changes during germination and subsequent outgrowth in a nutrient medium, was followed by electron microscopy. Dissolution of the spore cortex was accompanied by escape of cortical material via numerous perforations in the spore coat. The spore core underwent pre-emergent swelling to fill the space vacated by the cortical material, and eventual rupture of the spore coat led to emergence of the germling cell which invariably occurred via the open base of the exosporium. Thus, specimens of residual spore 'husks', prepared by the critical point drying procedure, consisted of intact exosporia enclosing surprisingly large fragments of the original spore coats.
\end{abstract}

\section{INTRODUGTION}

The course of spore activation, germination and outgrowth in Clostridium is basically similar to that in Bacillus (Gould, 1969; Walker, 1970) though in certain species of Clostridium the sequence of events has some unusual features (Hoeniger \& Headley, 1968; Samsonoff, Hashimoto \& Conti, 1970). Having found that the exosporium of autolytically liberated spores of Clostridium pasteurianum is open at its base (Mackey \& Morris, I97I, 1972), we wished to determine whether the emergent germling cell would invariably exit through this opening. In that event, it might be possible to exploit the resulting suspension as a source of quantities of essentially entire exosporia (though probably still containing spore coat fragments). This paper reports that rapid germination of a washed suspension of spores of C. pasteurianum was provoked by treatment with calcium dipicolinate, a procedure previously employed with spores of both Bacillus and Clostridium species (Keynan, Murrell \& Halvorson, 196I; Riemann \& Ordal, 196I). The ensuing temporally ordered sequence of ultrastructural changes which comprises germination and outgrowth in C. pasteurianum is described.

\section{METHODS}

Organism. Washed suspensions of autolytically liberated spores of Clostridium pasteurianum (strain W-5) ATCC 60I3, were prepared as previously described (Mackey \& Morris, 1972).

Germination. An aqueous suspension of spores $\left(5 \mathrm{ml} ; 4.5 \times 10^{8}\right.$ spores $\left./ \mathrm{ml}\right)$ was heated at $80^{\circ} \mathrm{C}$ for $10 \mathrm{~min}$. The spores were then harvested by centrifuging at $5000 \mathrm{~g}$ for $\mathrm{I} 0 \mathrm{~min}$, and were resuspended in $\mathrm{Io} \mathrm{ml}$ of a 'germination medium' containing (per 1): dipicolinic acid, $5.5 \mathrm{~g} ; \mathrm{CaCl}_{2} .6 \mathrm{H}_{2} \mathrm{O}, 80 \mathrm{~g}$; yeast extract (Oxoid), $3 \mathrm{~g}$; casein hydrolysate (Oxoid), $10 \mathrm{~g}$; 
glucose, $5 \mathrm{~g}$; L-cysteine. $\mathrm{HCl}, 0.5 \mathrm{~g}$; $\mathrm{NaHCO}_{3}, 4.2 \mathrm{~g}$; all adjusted to $\mathrm{pH} 7$ with $\mathrm{KOH}$ and presterilized by autoclaving at $\mathrm{I}_{5} \mathrm{lb} / \mathrm{in}^{2}$ for $\mathrm{I} 5 \mathrm{~min}$. The spore suspension was lightly coloured with methylene blue, and sodium dithionite was then added until the blue colour had disappeared. The suspension was finally incubated for approx. $30 \mathrm{~min}$ at $37^{\circ} \mathrm{C}$ in an atmosphere of $\mathrm{N}_{2}$ plus $\mathrm{CO}_{2}(95: 5, \mathrm{v} / \mathrm{v})$; at the end of this period, the spores had lost their initial refractility.

Outgrowth. Germinated spores were harvested by centrifugation ( $5000 \mathrm{~g}$ for $\mathrm{I0} \mathrm{min}$ ), and were resuspended in $200 \mathrm{ml}$ of 'outgrowth medium' contained in a $250 \mathrm{ml}$ 'Pyrex' glass culture vessel provided with the means of monitoring $E_{\mathrm{h}}$ and $\mathrm{pH}$ changes (O'Brien \& Morris, I97I). The 'outgrowth medium' contained (per I): yeast extract (Oxoid), $3 \mathrm{~g}$; peptone (Oxoid, L37), Io g; 'Lab Lemco' beef extract (Oxoid, L29), 8 g; glucose, 5 g; L-cysteine. HCl, $0.5 \mathrm{~g} ; \mathrm{NaHCO}_{3}, 4.2 \mathrm{~g}$; all adjusted to $\mathrm{pH} 7$ after autoclaving at $\mathrm{I}_{5} \mathrm{lb} / \mathrm{in}^{2}$ for ${ }_{5} 5 \mathrm{~min}$. While maintaining the culture at $37^{\circ} \mathrm{C}$ in an atmosphere of argon, sodium dithionite was added until the $E_{\mathrm{h}}$ was approximately $-370 \mathrm{mV}$; samples were thereafter removed at intervals for examination by phase contrast and electron microscopy.

Electron microscopy. The procedures employed have been fully described (Mackey \& Morris, 1971, 1972).

Materials. Dipicolinic acid (pyridine 2,6-dicarboxylic acid) was purchased from KochLight Laboratories Ltd, Colnbrook, Buckinghamshire.

\section{RESULTS}

\section{Rapid germination provoked by calcium dipicolinate}

Although anaerobic incubation of heat-shocked spores of Clostridium pasteurianum in either a minimal glucose, ammonium, salts and vitamins medium (Mackey \& Morris, 197I) or a rich, semidefined medium (e.g. reinforced clostridial medium, Oxoid CM r 49) resulted in eventual growth of a vegetative culture, the proportion of spores which germinated and proceeded to the stage of outgrowth in these media was too low for these events to be conveniently studied by electron microscopy. However, exposure to calcium dipicolinate, provided as one ingredient of a nutritious medium, resulted in rapid germination of a very high proportion of the spores; approx. $90 \%$ of spores germinated within 20 min when incubated at $37^{\circ} \mathrm{C}$ in 'germination medium' (see Methods). Provision of a negative $E_{\mathrm{h}}$ was essential, for very little germination occurred when this medium was not initially reduced by addition of sodium dithionite.

Since calcium dipicolinate might influence the course of postgerminative, ultrastructural changes, we transferred the germinated spores into a fresh, dipicolinate-free 'outgrowth medium' (see Methods), possibly at the cost of extending the time taken to achieve outgrowth. Emergent cells, viewed by phase contrast microscopy, were only seen some 2 to $3 \mathrm{~h}$ after transfer of the germinated spores to 'outgrowth medium'. Samples were removed every $0.5 \mathrm{~h}$ for electron microscopy but, since outgrowth did not occur synchronously, organisms in differing stages of morphological development were present in all of the early samples. The sequence of ultrastructural changes described in this paper is therefore our interpretation of the temporal course of events during the process of outgrowth, and its component stages cannot be exactly correlated with specified periods of incubation in 'outgrowth medium'.

\section{Ultrastructural changes during germination and pre-emergent swelling}

Very little structural detail was discernible in ultrathin sections of dormant spores of Clostridium pasteurianum (Mackey \& Morris, 197I) since, as in spores of other species, the 

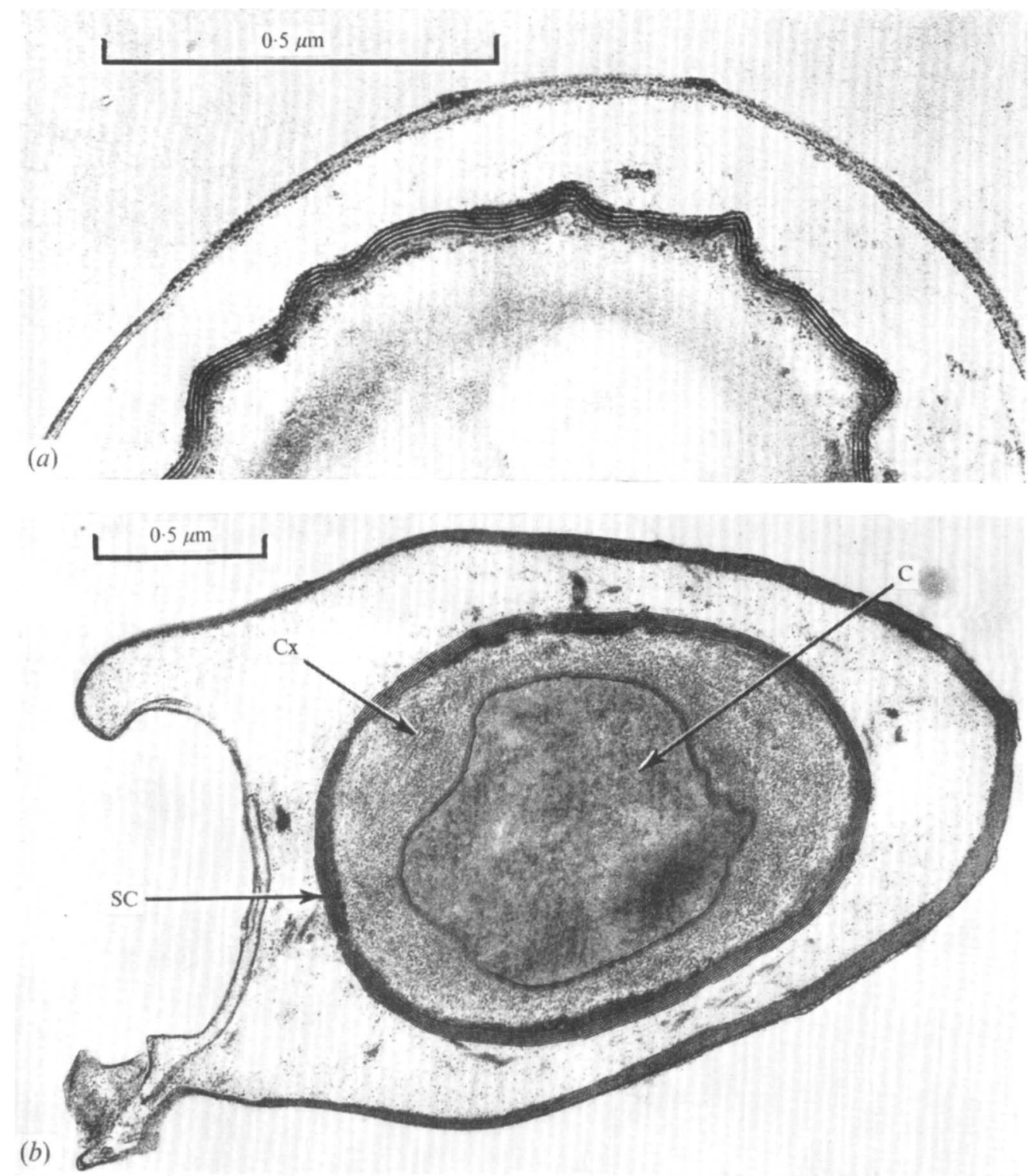

Fig. I. (a) Segment of section of heat activated spore of Clostridium pasteurianum. (b) Section of germinated spore of $C$. pasteurianum. $\mathrm{C}$, spore core; $\mathrm{Cx}$, cortex; $\mathrm{SC}$, spore coat.

cortex and spore core were probably poorly impregnated by the fixative and showed little affinity for heavy metal 'stains'. Sections prepared immediately following heat activation were not noticeably different (Fig. I $a$ ) but germination was attended by the usual enhancement of the spore content's affinity for stains. In sections of germinated spores which had lost the phase contrast refractility of dormant spores, structures (including nuclear material and ribosomes) were again discernible within the spore core (Fig. I $b$ ). In the specimen shown in Fig. I (b), the cortex had acquired a somewhat granular appearance and was already undergoing dissolution; some cortical material had exuded into the parasporal space, 


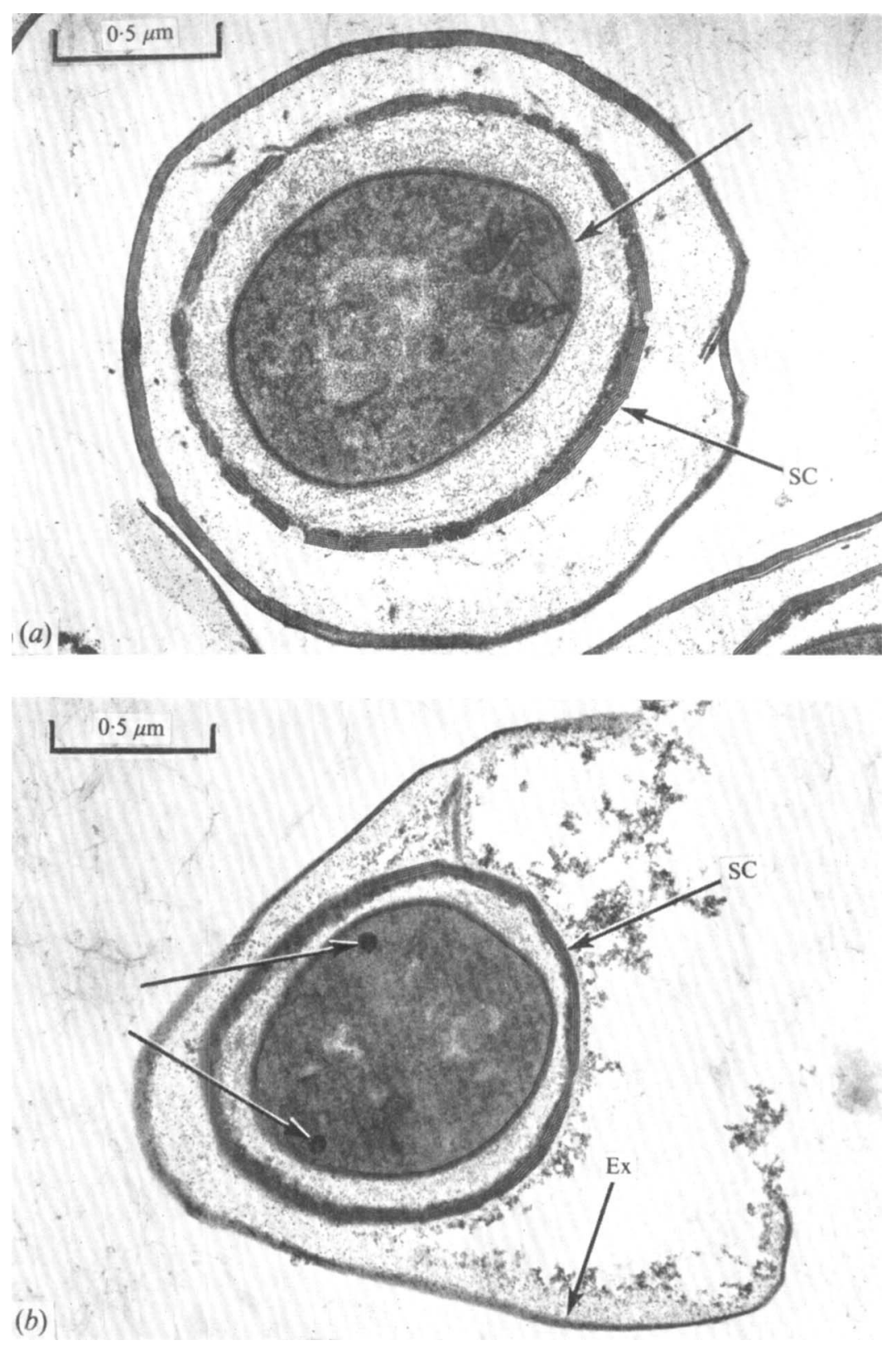

Fig. 2. (a) Transverse section of gerrminated spore of Clostridium pasteurianum at the stage of preemergent swelling. Numerous breaks are visible in the spore coat (SC), and in one zone (arrowed) the membrane which surrounds the spore core is considerably invaginated. $(b)$ Longitudinal section of germinated spore of $C$. pasteurianum showing loss of partly lysed cortical material into the parasporal space. Electron dense inclusion bodies (arrowed) are present in the spore core. SC, spore coat; Ex, exosporium. 
presumably via the small 'breaks' that had appeared in the multilamellar spore coat. The innermost layer of the cortex immediately enveloping the spore core was quite distinctly more electron dense and coherent than the remainder. In another germinated spore examined at approximately the same stage of pre-emergent swelling (Fig. $2 a$ ) the breaks in the spore coat were more numerous and in one zone the membrane surrounding the spore core was quite considerably invaginated, the lumen being filled with electron-dense, inner cortical layer material. The swelling of the spore core (evident in Fig. $2 b, 3 a$ ) was presumably due both to imbibition of water and to biosynthesis of new cell material (Strange \& Hunter, I969). In the specimen shown in Fig. $2(b)$, the cortex was manifestly diminished in width due to substantial loss of partially lysed, cortical material into the parasporal space; dense, darkly staining bodies of the type present in outgrowing cells of $C$. pectinovorum (Hoeniger $\&$ Headley, 1968) were quite frequently observed in the pre-emergent cell (Fig. $2 b$ ). The cortex had almost completely disappeared from the spore shown in Fig. 3(a), though the inner cortical layer, which may contribute to the primordial wall of the emergent cell, was still present below the residual spore coat; the spore core had swollen to fill the space vacated by the cortex.

\section{Emergence}

Following loss of the cortex, further swelling of the spore core ruptured the already weakened spore coat, and the emergent cell invariably exited via the open base of the exosporium, pushing ahead of it a considerable quantity of detritus including partly lysed cortical material and fragments of spore coat (Fig. $3 b, 4 a, 4 b, 6 a$ ). The emerging cell was not appreciably distorted or compressed during its passage through the fractured cell coat. In sections of cells emerging from their spore envelopes, there was occasionally present a major invagination of the cell membrane filled with primordial cell wall material (Fig. $3 b$, $4 b$ ). Though the significance of this is not known, it was of interest that this structure was always found toward the 'rear' of the emerging cell.

\section{Residual spore envelopes}

The newly formed cell completely vacated the remains of the spore, leaving a broken spore coat within its exosporium. Fig. 5 shows a transverse section of such a spore 'husk'. To obtain three-dimensional views of these spore remains, we employed the critical point drying technique (Mackey \& Morris, 1972). In Fig. 6(b) may be seen the hole in the spore coat through which the cell emerged prior to exiting through the open base of the exosporium. Even so, the fragile exosporium may be torn in this process (Fig. 6c).

\section{DISCUSSION}

Calcium dipicolinate was the most rapidly acting of the many possible germinants. The eventually emergent vegetative cells were apparently quite normal in structure and in their subsequent growth, metabolism and propensity to sporulate. Puncturing of the spore coat, presumably the result of activation of some specific lytic enzyme(s), occurred immediately following germination and coincident with the inception of cortical dissolution. This is reminiscent of the situation in Bacillus polymyxa (Murray, Hall \& Marak, 1970). Unlike germinating spores of Clostridium sporogenes which do not expand to fill the space originally occupied by the cortex (Hoeniger \& Headley, I969), the spores of $C$. pasteurianum underwent very evident pre-emergent swelling. In $C$. sporogenes emergence is a gradual process during which proteases secreted by the germinating cell digest first the spore coats and then the 

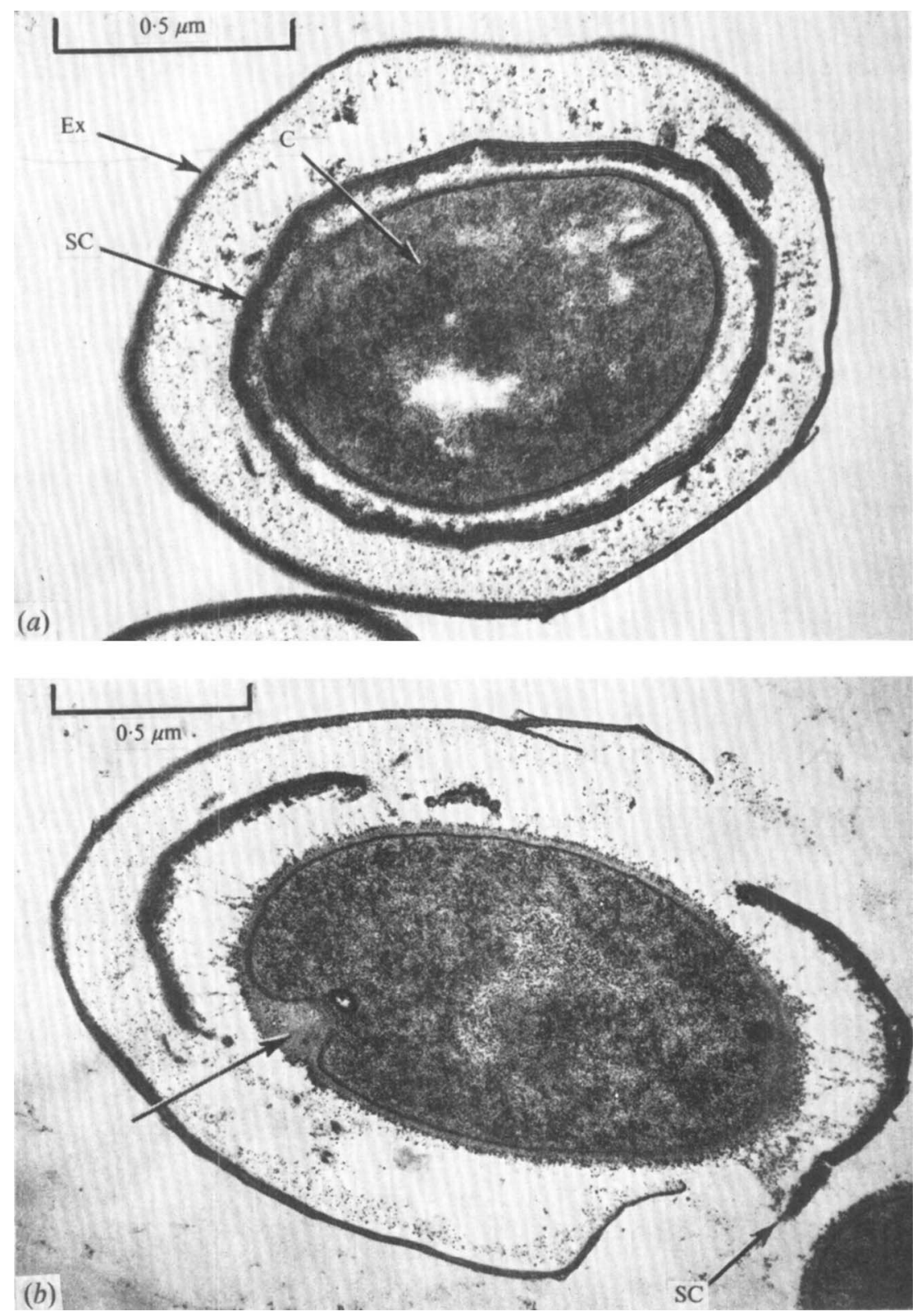

Fig. 3. (a) Transverse section of germinated spore of Clostridium pasteurianum showing swelling of core to fill the space vacated by lost cortical material. C, core; Ex, exosporium; SC, spore coat. (b) Longitudinal section of emerging germling of C. pasteurianum showing expulsion of fragments of spore coat (SC). A major distal invagination of the germling cell membrane is evident (arrowed). 


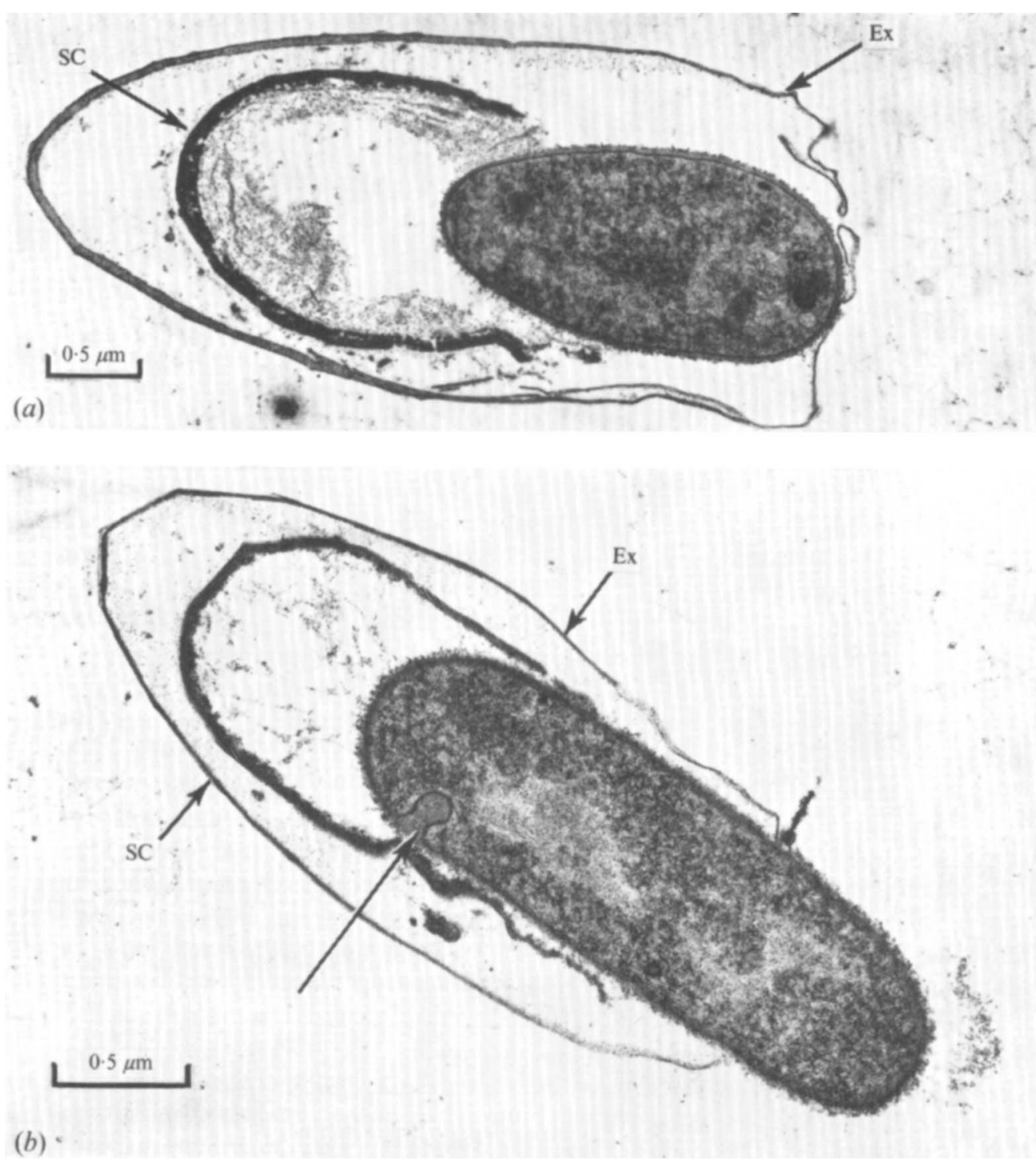

Fig. 4. Longitudinal sections of germlings of Clostridium pasteurianum emerging from their spore envelopes. Ex, exosporium; SC, spore coat. (a) Prior to emergence from the exosporium. (b) Exiting via the open base of the exosporium. The distal invagination of the cell membrane is again apparent (arrowed).

exosporium (Hoeniger \& Headley, 1969), while in C. pectinovorum the germling emerges with explosive rapidity via a ruptured but inflexible spore coat (Hoeniger \& Headley, I968). In $C$. pasteurianum the spore coat is evidently weakened prior to being penetrated by the emerging cell since this is not distorted as it exits from the spore envelopes. Having seen in section how the spore coat is perforated at several points (Fig. 2a) and how portions of the coat are broken off and expelled in the van of the outgrowing cell (Fig. $3 b$ ), it was surprising to find in critical point dried spore husks (Fig. $6 b, 6 c$ ) how much of the spore coat remained 


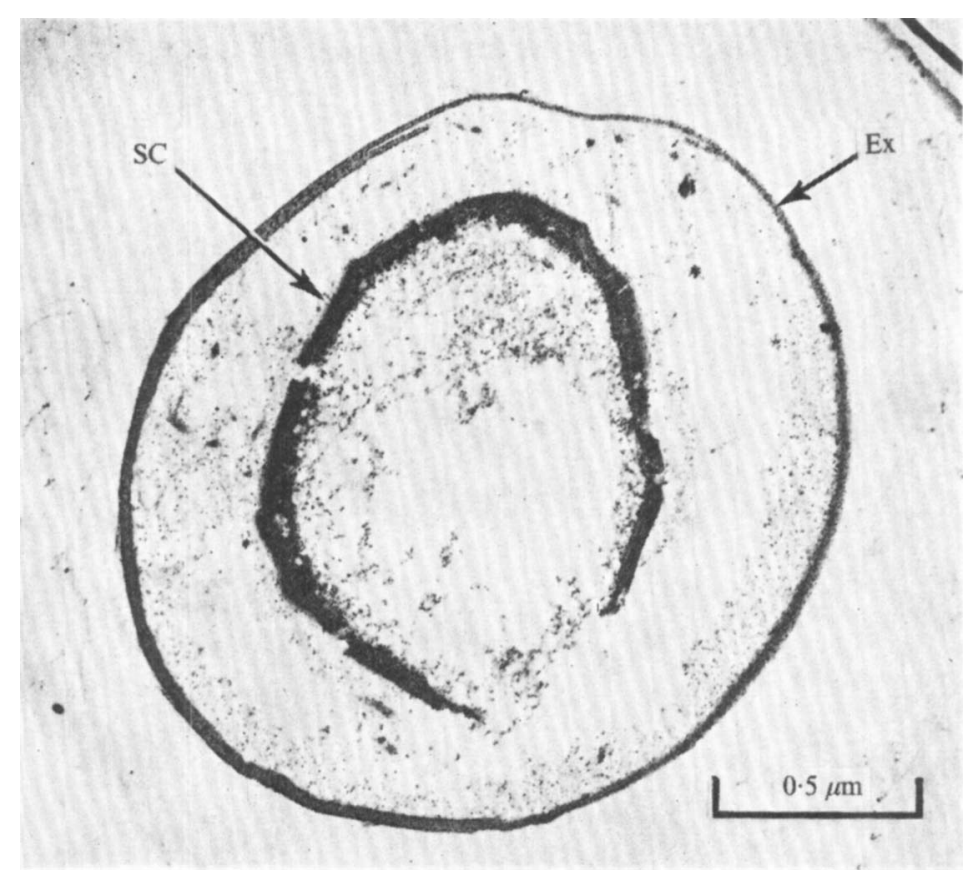

Fig. 5. Transverse section of residual, empty spore husk of Clostridium pasteurianum. Ex, exosporium; SC, spore coat.

seemingly entire after the emergence of the germling. This could mean that the relatively small perforations were obliterated in surface view by the remains of partially lysed cortical material which had exuded through them. Yet one must be particularly cautious when interpreting the appearance of specimens prepared by the relatively novel critical point drying procedure; for example, the apparently glutinous appearance of the exuded cortical material (Fig. 6a) could in part be due to solvent action by the ethanol and amyl acetate used in this procedure.

The emerging cell always exited via the open base of the exosporium; Propst \& Möse (1965) had reported that in Clostridium butyricum the germling similarly emerged from the base of the spore. They concluded that 'the future locus of expulsion of the organism from the spore envelope has already been determined in the spore . . . longitudinal growth would seem to be directed at this point and would indicate monopolar activity of the organism during this phase'. This tendency of the germling cell to emerge unidirectionally has also been noted in other species. Thus in C. bifermentans outgrowth was 'almost always' from the pole opposite the appendages (Samsonoff, Hashimoto \& Conti, 1970), and in C. pectinovorum 'the cell always emerges at the pole opposite the sporangial collar and involves progressive rupture of the inner coat, the outer coat and finally the sporangium' (Hoeniger \& Headley, I968). In these species therefore the cell exited from the opposite pole of the spore to that penetrated by germlings of $C$. butyricum and $C$. pasteurianum. Yet until more is known of the mechanism whereby the spore coat is broken, and of the forces which propel the growing cell from the remnants of its spore envelopes, we cannot with any certainty claim that the 'polarity' is inherent in the germinated spore core, though it is true that in 


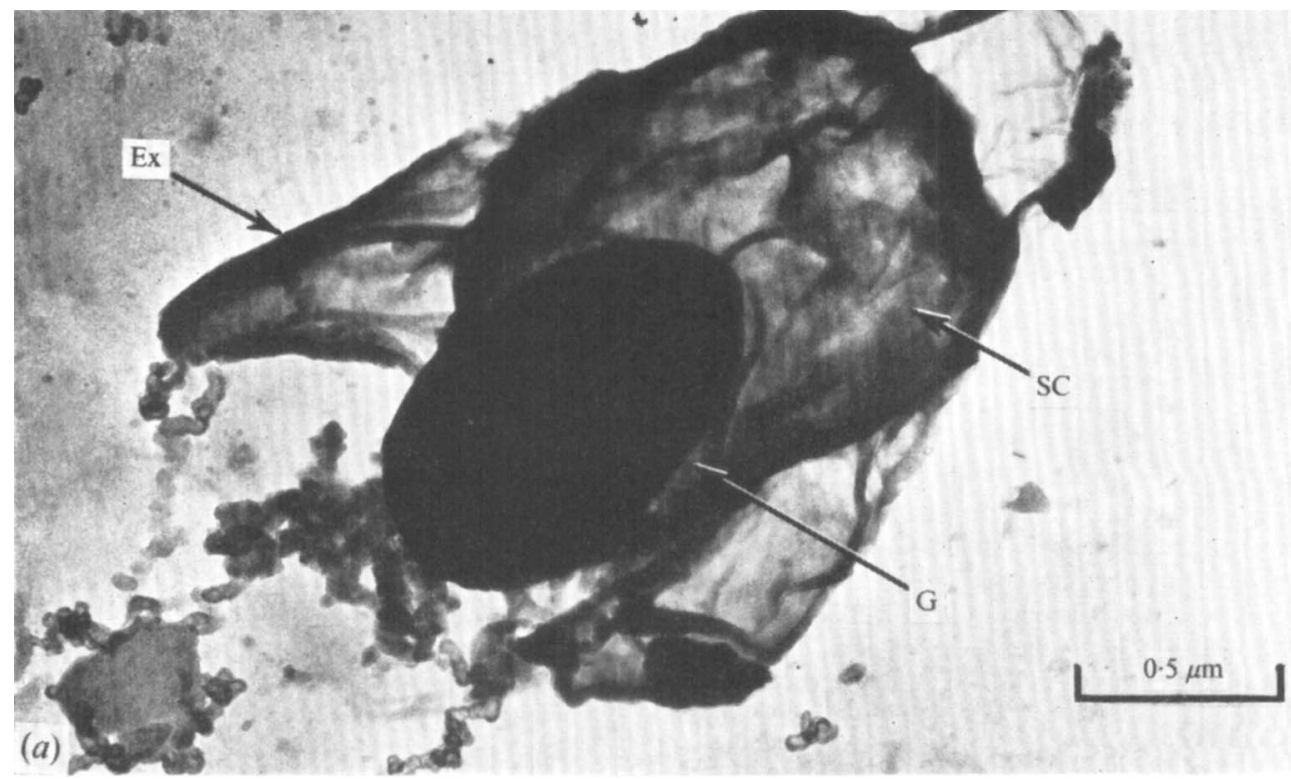

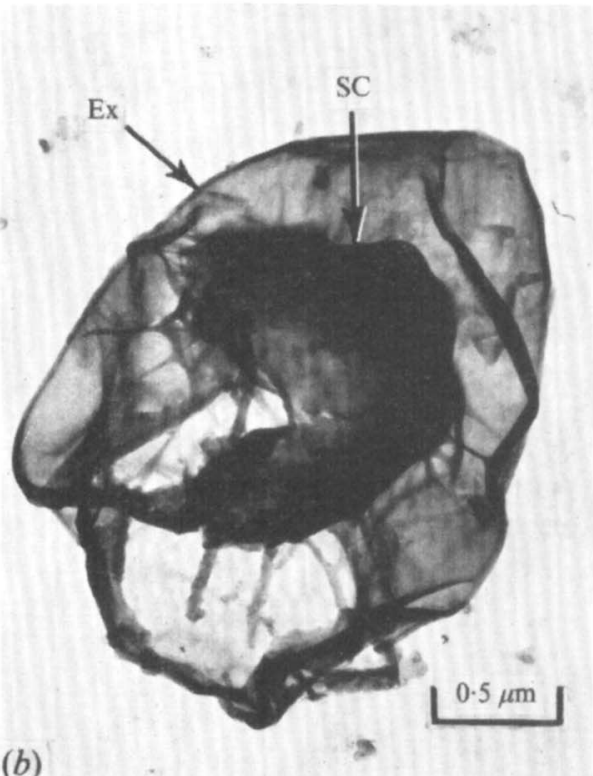

(b)

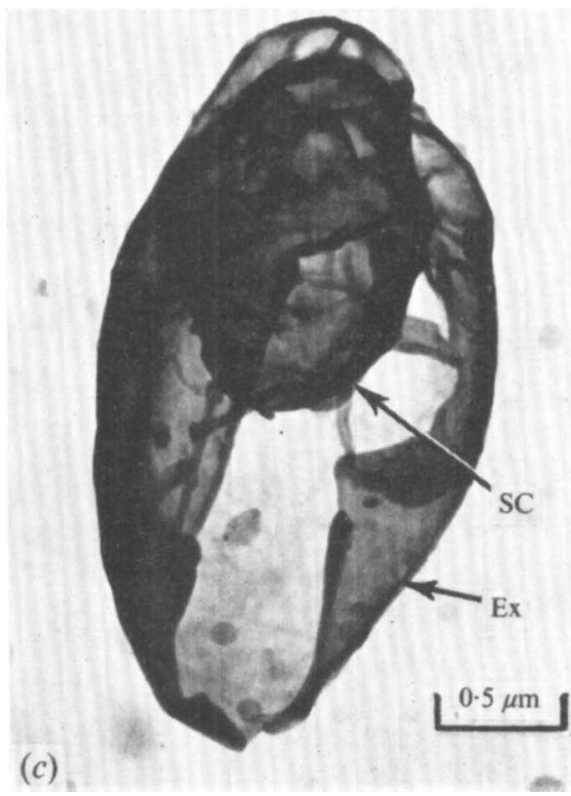

Fig. 6. Critical point dried specimens of outgrowing spore, and of residual spore husks of Clostridium pasteurianum. (a) Outgrowing spore showing partially lysed cortical material being expelled in the van of the emerging germling cell $(\mathrm{G})$. Ex, exosporium, SC, spore coat. $(b)$ Residual spore husk showing break in the spore coat $(\mathrm{SC})$. (c) Residual spore husk showing partly rent opening in the base of the exosporium (Ex). 
neither $C$. bifermentans nor $C$. pectinovorum does it seem as though the emerging cell takes the route of least resistance. In turn the fact that the germling emerges via the open end of the exosporium of $C$. pasteurianum does not constitute proof that the opening exists for this purpose. It will be interesting to discover whether the perforations and terminal rupture of the spore coat in this species is caused by enzyme(s) incapable of similarly acting on the exosporium. The spore husks present at the end of incubation in 'out-growth medium' may prove useful substrates in such a study.

This work was supported by a grant from the Science Research Council.

\section{REFERENCES}

Gould, G. W. (1969). Germination. In The Bacterial Spore, pp. 397-444. Edited by G. W. Gould \& A. Hurst. London: Academic Press.

Hoeniger, J. F. M. \& HeAdley, C. L. (1968). Cytology of spore germination in Clostridium pectinovorum. Journal of Bacteriology 96, $1835-1847$.

HoENIGER, J. F. M. \& HeADLEY, C. L. (1969). Ultrastructura] aspects of spore germination and outgrowth in Clostridium sporogenes. Canadian Journal of Microbiology 15, 106 I-1066.

Keynan, A., Murrell, W. G. \& Halvorson, H. O. (196r). Dipicolinic acid content, heat activation and the concept of dormancy in the bacterial endospore. Nature, London 192, I 21 I-I 2 I 2.

MACKEY, B. M. \& MORRIS, J. G. (197I). Ultrastructural changes during sporulation of Clostridium pasteurianum. Journal of General Microbiology 66, $\mathrm{I}-\mathrm{I} 3$.

MACKEY, B. M. \& MORRIS, J. G. (1972). The exosporium of Clostridium pasteurianum. Journal of General Microbiology 73, 325-338.

MurRay, R. G. E., Hall, M. E. \& MaraK, J. (1970). Maturation of cell wall structure during germination of Bacillus polymyxa spores. Canadian Journal of Microbiology 16, 883-887.

O'BrIEN, R. W. \& MorRIS, J. G. (I97I). Oxygen and the growth and metabolism of Clostridium acetobutylicum. Journal of General Microbiology 68, 307-318.

Propst, A. \& MösE, J. R. (1965). Electronenmikroskopische untersuchung der keimung des Clostridienstammes M55. Zentralblatt für Bakteriologie, Parasitenkunde, Infektionskrankheiten und Hygiene (Abteilung I) r95, 500-509.

RiemanN, H. \& ORDAL, Z. J. (1961). Germination of bacterial endospores with calcium and dipicolinic acid. Science, New York I33, 1703-1704.

SAMSONOFF, W. A., HASHimoto, T. \& Contr, S. F. (I970). Ultrastructural changes associated with germination and outgrowth of the appendage-bearing clostridial spore. Journal of Bacteriology 101, I038-1045.

StRANGe, R. E. \& HUNTER, J. R. (I969). Outgrowth and the synthesis of macromolecules. In The Bacterial Spore, pp. 445-483. Edited by G. W. Gould and A. Hurst. London: Academic Press.

WALKER, P. D. (1970). Cytology of spore formation and germination. Journal of Applied Bacteriology 33, I-I 2. 